\title{
The constraint and liberation of urban morphology in Algiers
}

T. Shen

The Bartlett School of Architecture, University College London, UK

\begin{abstract}
What is the relationship between urban morphology and transportation infrastructure? As neutral reference lines for future urban organization, the transportation have not only influenced the initial urban structure, but also behaved as the carrier of dynamic circulations. Although such highway and railway systems have underpinned the city vitality, stimulated productivity and population mobility, these large-scaled structures have also led to the urban splintering. Taking Algiers as case study, this paper examines the inter-dynamic elements between transportation development, urban morphology changing and social collective activities. On the one hand to illustrate, these infinite infrastructures tend to segregate the metropolitan regions, traverse the urban form and constrain regional organization. On the other hand, as Made in Tokyo suggests, such new spaces shaped by transportation infrastructures are actually valuable, not only because they are opportunities for making the best of limited space in the dense city center, but also revitalising accessibility from the center to the surrounding area. While one indicates a regional planning perspective, the other deals with an existing plan, architecture and social aspects.

Keywords: urban morphology, transportation infrastructure, circulation, interactional relations, urban splintering, urban sprawl.
\end{abstract}

\section{Introduction}

Urban morphology is defined as a structure, which is dimensionally or symbolically relevant to street and building patterns [1]. Taking Algiers as an illustration, from the triangle-shaped town (Casbah, 16th century) to the new industrial metropolis (Hamma, 20th century), the geometric system of grand infrastructure shows a feature of vectoring urban construction as well as shaping 
forms. Based on the circulation, transportation is a crucial element of power shaping a place [2]. It can encourage social activities and bring together separated neighborhood fragments as well as divide them. As such monofunctional flow (human or tailored for high-speed mobility only) and hybrid flow (human, vehicular, products) are important factors shaping the urban fabric, considering the urban environment as a whole unit may help to rethink the meaning of the transportation infrastructure influencing the urban textures.

According to the sequence listed in Figure 1, within 200 years or so, Algiers has been extended from $0.36 \mathrm{~km}^{2}$ to $1,190 \mathrm{~km}^{2}$, from constraint to liberation along the complicated vertical and horizontal transportation infrastructures (row 1 ); Zooming into the block scale in row 2, matrices of figure-grounds indicate the relationship between street networks and urban fabric has been transformed into a weakened condition over time; Further taking into architecture scale, easily accessible neighbourhoods seem to share certain characteristics of street and community forms, while ones which lack of communication are always obstructed by the surrounded huge infrastructures.
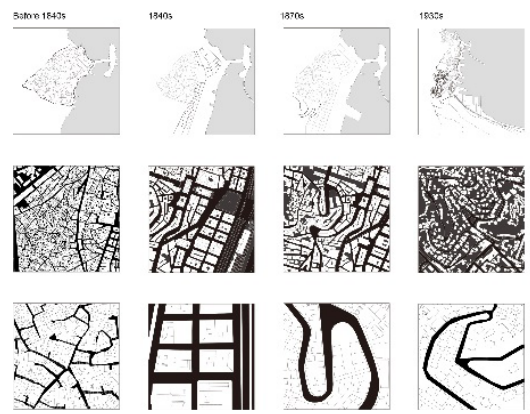
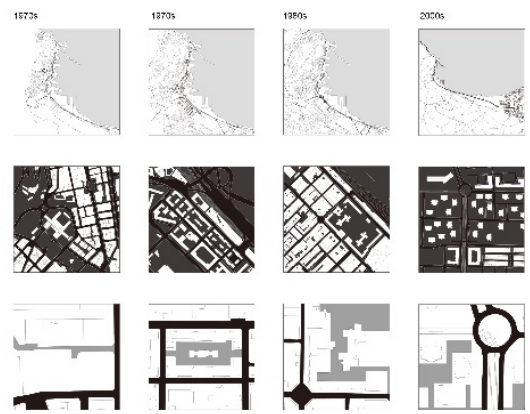

Figure 1: The timeline of urban morphology changing along with transportation infrastructures development. From territory scale (row 1), block scale (row 2) and architecture scale (row 3).

Based on these phenomena, are there any mechanisms behind these transportation infrastructure typologies to predict future urban morphology changing, and how could we use these facilities to form the urban space we want in the future?

\section{Outline of urban structure development}

In terms of its dual sense of 'splintering' and 'articulation', consistent with public conveyance improvement, the interactional relations between transport infrastructure and associated spatial samples in Algiers could be summarised by the following sequences: 
Table 1: Interactional relations between transport infrastructure and associated spatial samples.

\begin{tabular}{|l|l|}
\hline Before the 1840s & Medinas, street life only, infrastructure as scattered ports \\
\hline $\begin{array}{l}\text { From the 1840s to } \\
1920 \mathrm{~s}\end{array}$ & $\begin{array}{l}\text { Appearance functional zoning, infrastructure } \\
\text { regularisation expanding the city }\end{array}$ \\
\hline $\begin{array}{l}\text { From the 1920s to } \\
1960 \mathrm{~s}\end{array}$ & Networked transportation tailored to logistics \\
\hline After the 1960s & $\begin{array}{l}\text { Fordist production completed the interconnection } \\
\text { between transportation junctions }\end{array}$ \\
\hline
\end{tabular}

From the table above we could conclude the factors mainly form: the modes of transportation, industrialization and road hierarchy. Charles has argued that the history of the modern city, or modernism, is the history of movement [3]. Furthermore, after the following examples to explain both global and domestic background of why a certain type emerged, we could say that the history of transportation is the history of infrastructure. Overall, infrastructure and circulation lead the form and scale of urbansation [4], influencing not only cities' physical extents and morphology but also invisible social relationships (i.e. French colonial police power and ethnic Muslim rules).

\subsection{Traditional Muslim city}

\subsubsection{Medina, Casbah, 16th century, coexist}

Limited in terms of its transportation networks, the mono-functional walking system tightened pressure on urban land use (over 93\% of the land) and hindered the city sprawl. Under such a circulation system, social activities normally happened in a small unit, i.e. family clans and tribes. At that time, the flow of indigenous human activities replaced the city form, which was not a fixed entity, but a process of organisation along the main roads (Figure 2).
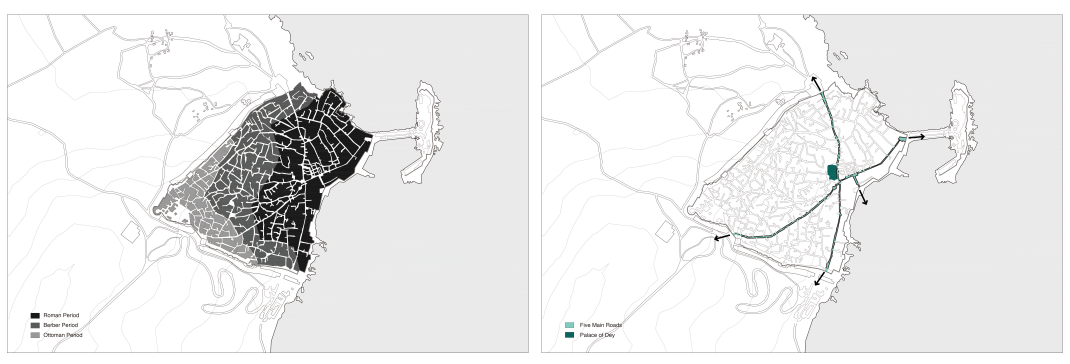

Figure 2: Three stages of Casbah city sprawl along the 3 main roads. 
To be more specific, in accordance with Islamic beliefs, religion was a crucial element of political supremacy power in shaping this organic fabric [5]. Thus at that time, roads were likely to be built in spaces left by buildings rather than according to a sophisticated planned structure.

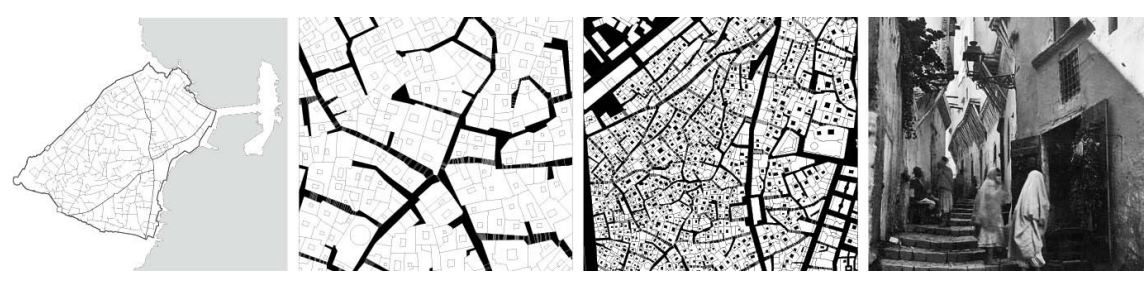

Figure 3: Medina, Casbah, 16th century, coexist.

\subsection{Industrial regeneration zone}

Under context of booming industrial development, coinciding with the rise of Fordist processes, the treatment of all the spatial networks was translated to a local scale [6], having features of a complex and territorially dispersed system. In order to coordinate the demands of this expanding stage and the logistics requirement, a new model of urban planning was created because of these network infrastructures.
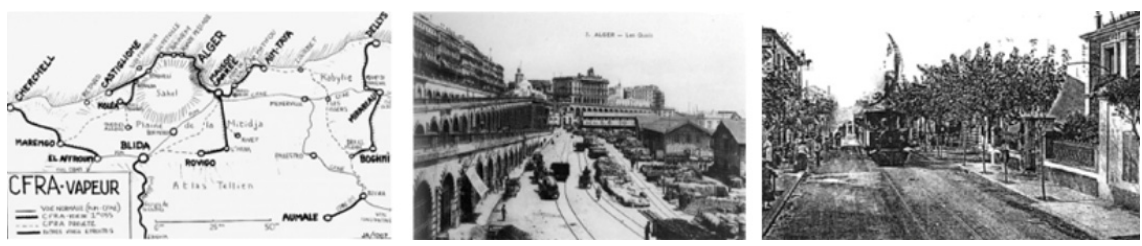

(Source: Perspectives de la multi modalité à Alger Tahar BAOUNI Ecole Polytechnique,

d'Architecture et d'Urbanisme (EPAU) d'Alger).

Figure 4: CFRA (Company of Railways on Roads Algeria) operated six electric trams and three railways.

From the 16 th to the mid-19th century, the city expanded three times along the railway and tramlines. Founded in 1892, CFRA (Company of Railways on Roads Algeria) operated six electric trams and three railways (Figure 4) to link the different centres in Algiers. From Casbah to the governance centre at Hamma, the five stations centralised the scattered neighborhood fragments into the hubs. Later on, since vehicles evolved and efficiency was prioritised, long block street networks superseded the original narrow pedestrian roads. Henceforth, a new 
type of urban morphology was emerged, and the original dense urban grids became less dense but had larger plots. These polycentric cities were in an embryonic form, and were created as a counterpoint to low density and decentralisation through the construction of the trunk links. Compared to the urban planning stratagems in the same time period, like Garden City (Howard, 1898) and Satellite Town (Unwin, 1922), these urban structures shared characters of decentralism and interconnection.

To sum up, with the zoning functions of religion, leisure, transportation, governance and commerce, subordinate city centres were constrained by the combined flow of human, vehicular and product transport. Consequently, public transport on the one hand enhanced the strength of land development along the transportation circulation, on the other hand made the population density drop to 50-100 people per hectare [7]. The development of urbanism carried out by means of generation ameliorative infrastructural capital [8], which means domain focus on improving the infrastructure condition, in essence is always a means of promoting accessibility. Taking the following two samples as demonstrations:

\subsubsection{French colonial stage, $1830 \mathrm{~s}$, perimeter}

In the 1830 s the French introduced a so-called 'Rational Street' system in Algiers (Figure 5). Given the historical context of Haussmann's renovation of Paris between 1853 and 1870, Algiers industrial zone seemed to require 'regularisation', much like the French boulevards, which were more easily accessible [9]. Considering the relationships of buildings and circulation to the forming of urban fabric and morphology, the building was designed as an entire corridor for commercial uses and could be accessed form four sides. Such typical building form, which had occupied the whole block with a pedestrian colonnade, coexisted with the street network.

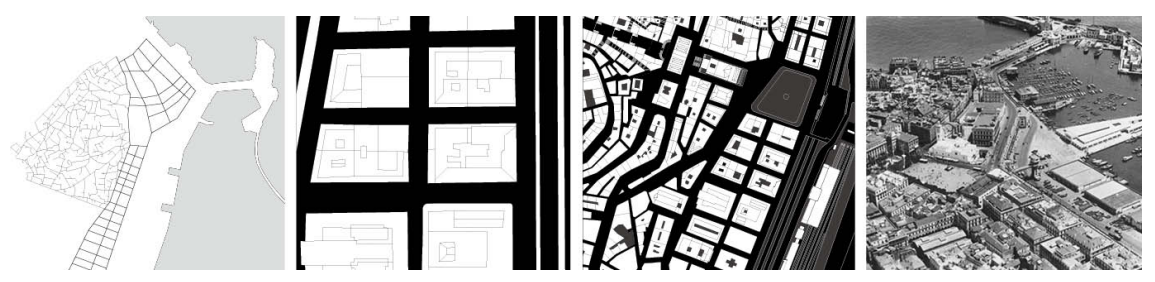

Figure 5: French Colonial stage, 1830s, perimeter.

This urban structure gave the city context a new order through combining land use and construction of integrated infrastructure networks. Firstly, the rational urban form was designed to encourage free circulation both within and between cities [10]; secondly, the social and physical fabrics also gave unity to and transformed the operative whole of the industrial chain both over and underground. The road and sewer networks were planned to be a general circulatory system with hierarchical tributaries linking the new plaza nodes [11]. 
To sum up, in the wake of tramlines and railways being widely used at the end of 19th century, the suburban sprawl clearly started alongside transportation nodes. Compared to the alleys in Casbah, the urban morphology represented by the rational French boulevard appeared as wide, straight and well connected to the urban grid. The perimeter relationship between street networks and urban blocks created a new way of organising urban space. Moreover, although coverage was only $45 \%$, the high FAR (4.2) of these urban blocks enhanced the business values of nearby city districts. It meaningfully connected the dispersed parts of the modern industrial city into an organic whole, thereby supporting its wider role as a dominant national and international metropolis [12].

\subsubsection{0s, topographic block edge}

After the conquest of the whole country, the French policy towards Algiers tried to combine Muslims indigenous to the country with French society to absorb more labors. At that stage, transportation circulation served as a way of organising social rank as well as reflecting political power intervention. Resulting from the continual arrival of European immigrants (estimated 21,000 at the end of 19th century) the city sprawl into the mountain areas with high density. For instance, taking Rue Rovigo as an example the road extended into back hills with its dramatic curve shape (Figure 6), providing connection between the city front and marine part to the upper local areas [13].
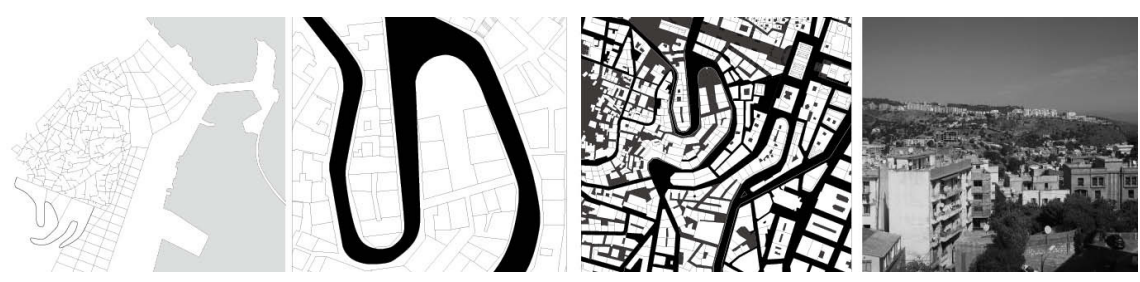

Figure 6: 1870s, topographic block edge.

Thus, the new urban morphology displayed a strong topographic character that showed an exact match along with the road form. On account of policy, population and territory condition, urban morphology was not only influenced by the physical community but also social relationships, such as economic relationship, political and productive relations.

\subsection{Coastal area and satellite area}

After World War II, the steam engine had been widely used [14]. Meanwhile, as the highway system was created, vehicles made the city sprawl possible in any direction where there were roads. Such infrastructures bound peripheral rural areas with urban spaces as a coherent whole. In effect, these systems evolved from Haussman's regularisation plans, which determined the urban sprawl in an infinite way. Based on the urban grid, this plan created a series of closed hierarchical ladder style urban highways rather than an open urban street system 
[15]. At that time, the skyway, elevated inner ring road and viaduct became symbols of urban morphology. To be more specific, this kind of continual transition of Algiers's land development took place between the different rail lines as an important role in forming the city into lower density and liberation.

\subsubsection{0s, topographic free standing}

As Figure 7 illustrates, during the industrialization period, the spaces between houses became larger, which created a loose topographic fabric. These conditions first appeared in the late 19th century London then were evident in all the big cities. As a consequence of easy accessible to job opportunities, the Garden City's initial idea of coping with such overcrowding and housing challenges [16] was such a symbolic urban morphology formed by speedoriented networks. Similarly, taking advantages of lower land prices, the planning of Algiers tended to distribute large populations into suburban and countryside areas [17]. Thus, limited urban space was no longer a problem and buildings stood freely as a consequence of urban centre relief.
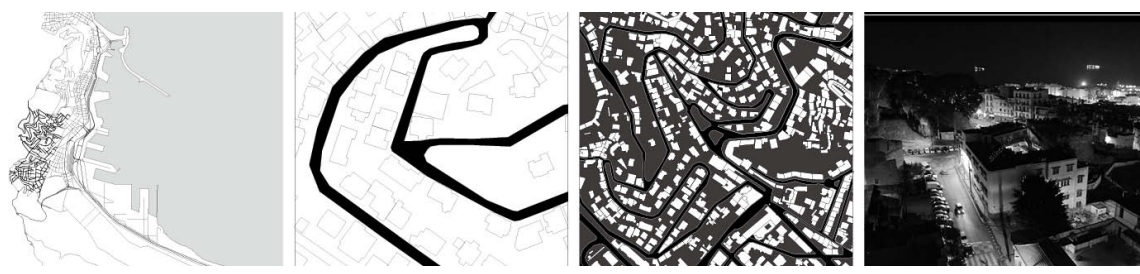

Figure 7: 1930s, topographic free standing.

\subsubsection{0s, big block}

Thanks to the influence of automobile production lines, cars were introduced into ordinary families in the 1970s [18]. Consequently, instead of walking and taking public transport, people started to drive more. Therefore the new urban structure appearing with fewer nodes, were required for quicker movement and less congestion, which in turn resulted in big urban blocks. With inner circulation to adjust its large depth, in an overall scale, the transportation infrastructure to a large extend played the role in splintering urbanism, which caused the building and human scale activities mainly relied on the inner circulation. Therefore, compared to the previous city fabric, the urban morphology of this time showed less dense with larger plots (Figure 8).
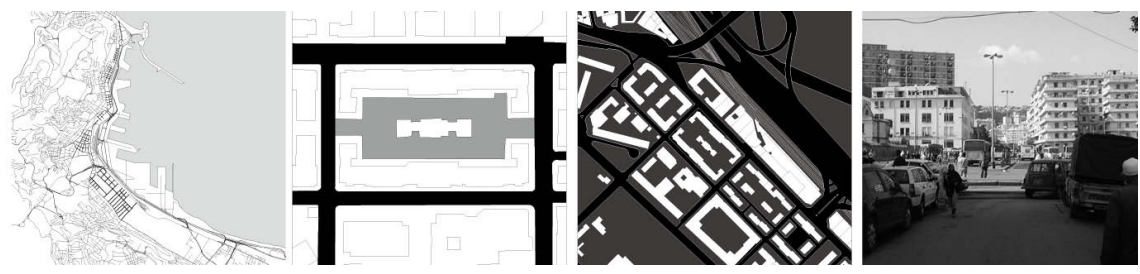

Figure 8: 1970s, big block. 


\subsubsection{0s to now, tower}

The continuous housing shortage stimulated the construction of high-rise towers in suburban areas, which used the transportation infrastructure as a connection from the centre to suburban areas, from working districts to residential areas. As a result of zoning regulation and the function of new residential areas was monotonous only for leaving in the frame of fast urban sprawl, the direct connection between the buildings and streets was not that necessary, resulting in districts of only towers. The investment in rapid transportation such as expressways made it possible to develop further suburban areas (Figure 9).
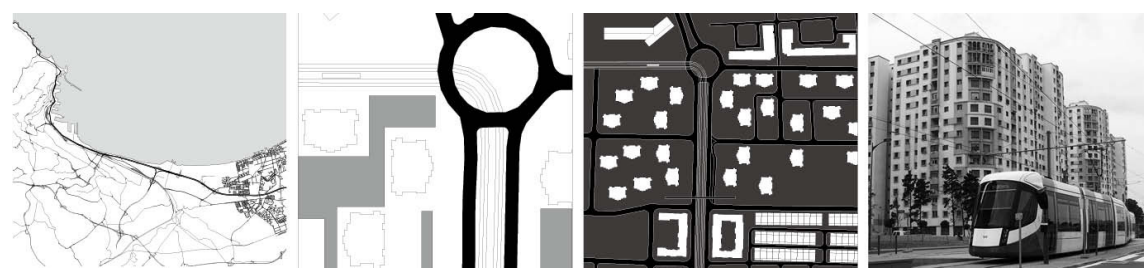

Figure 9: 2000s, tower.

By means of changing the accessibility and interactional relationships between streets and buildings, after 1900s the development process of Algiers formed a hybrid traffic flow. The ring roads and radial road traffic layouts changed the rule of reciprocal action and reaction between transportation and urban land use. By reducing travel costs, the movement of people towards inhabitation and commercial production regions has improved. The high-rise buildings are always constructed near transportation nodes. The corollary of this tendency is, these regions will be highly developed and change the urban morphology in future.

\section{Transportation infrastructures in forming space}

By observing transportation infrastructure and urban morphology changing in Algiers, the summary statistics below (Figure 10) reflect the unique features of 8 prototypes of urban form in Algiers. But comparing those types and their factors in each time period, what quality of space do they create in order to permit and foster certain urban form?

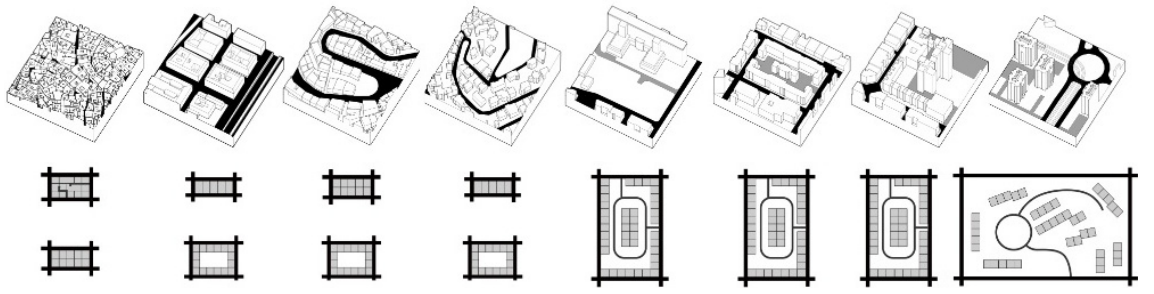

Figure 10: 8 prototypes of urban form in Algiers. 


\subsection{Spatial behavior}

Go through the urban form changing, the prototype of building with a 'double street frontage' changed to that with 'inner circulation', and the community as a result showed to be more self-organised with a trend of large scale blocks. Meanwhile, the access modes from the street in Algiers also gradually transformed. Comparing these typologies and their factors in each time period the complexity of transportation infrastructure not only resulted in physical interactions between the network and block form, but also influenced human behaviors. These factors suggest that the essential character of a city's land use results from how it manages its transportation [19].

\subsection{Spatial relation}

It is obvious form the following urban block matrices of Algiers (Figure 11) that the relationship between transportation infrastructure and urban fabric is transformed to a weakened condition over time. Although this is not the only reason, the complicated vertical and horizontal use of infrastructures with scale and objects changing gradually shaped Algiers' dense urban fabric. Because of the hierarchical features in the city, the transport network is always inserted into the urban fabric with different functions and scales.
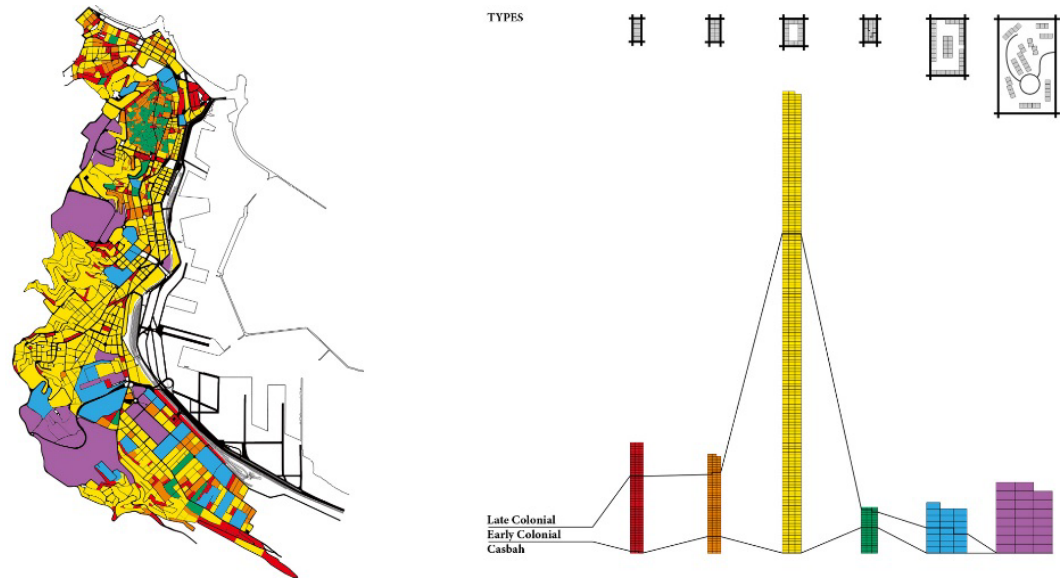

Figure 11: Percentage of certain transportation infrastructure typology formed urban morphology.

To sum up, from the regional planning perspective, Algiers' urban structure changed from being 'homogenous' into 'heterogenous'. The city structure was converted from constraint to liberation in both urban and block scale. In other words, before the industrial revolution, the mono-centric homogenous urban morphology could well maintain the city, which however fell prey to the 
bidirectional needs of global capitalism and industrialism. However, Conzen stated [20] that "particularly in the developing countries, urban sprawl occurred at an unprecedented speed because of the strength of their enormous infrastructures', which in turn revealed that the urban transportation system had been bound up with the wider urban constellation.

As Aldo Rossi has indicated [21], the urban fabric was breaking into 'patches'. Thus, organise and interplay 'patches' in a collaborative and accessible way is particularly important for the city's stability growth. As the diagram illustrated (Figure 12), once the fragment emerged, increasing the accessibility could be an efficient way to achieve homogenous. By means of connection by the transportation facility, an easily accessible way helps the heterogenous city change into a quasi-homogenous one.
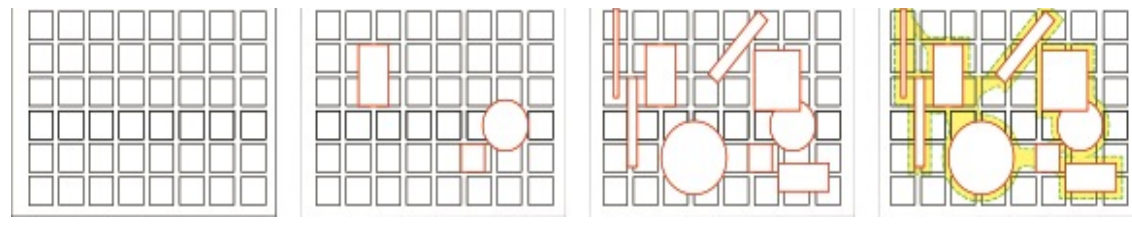

(Source: http://www.deshaus.com/research1.htm)

Figure 12: Increasing accessibility by connection to cope with urban fragments.

\section{The ambitions of combinatory new forms of urbanism}

Looking back the city construction experience, it seems that planned geometric frameworks were used to build up the city structure and manage the street order. As is known to all, the first step of change a virgin space into a value-added urban construction site is to cut through the urban grid. Undeniably, in the community, the more accessible the area is, the greater it has growth potential [22]. But only with the help of an easily-accessed infrastructure is not enough to steer urbanism. Urban formation is accumulated by overlapped networks with social aspects i.e. finance, immigration, communication and so on. With respect to the situation in Algiers from 1977 (Figure 13), in the overall context of dramatic population upswings because of immigration, there was a dramatic population decrease in the downtown and the hypercentre. To Bhabha [23], the mechanism behind such a phenomenon was that the population demanded more than the modern infrastructure supplied. With regard to the view of Tarr and Dupuy [24] small islands of infrastructure were joined up, integrated and consolidated towards standardised, regulated networks designed to deliver predictable, dependable services across Algiers. Thus, using the relationship between urban morphology and circulation, the negative space could be stimulated and changed into active. So, according to the research, we suggest to make the city more coherent as a whole by the following methods: 

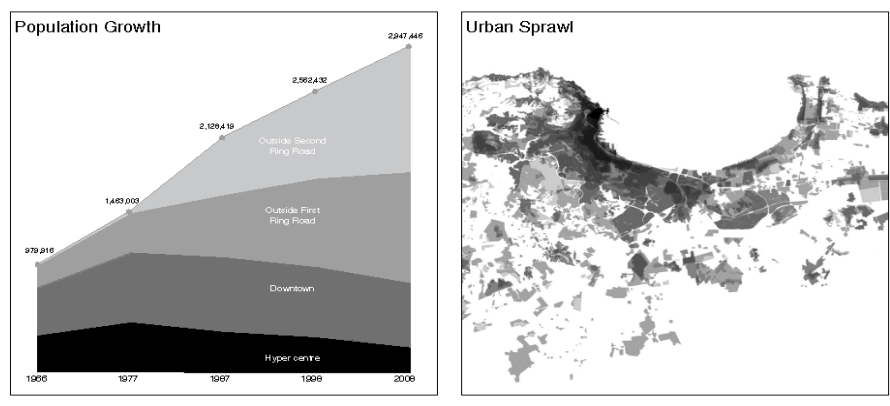

Figure 13: Dramatic population decrease in the downtown and the hypercentre under the context of urban sprawl and dramatic population upswings.

\subsection{Multilayered connections}

Taking advantages of multilayered connections between the existing and surrounding environment, the traversed neighborhood caused by the giant infrastructure could be reconnected by means of increasing diversity of the transportation facilities [25]. Thus, the transportation infrastructure could be ameliorated into a carrier of diverse circulations to achieve that. Especially in suburban districts, by means of special transportation reorganization, the segregated blocks could be connected by nature, culture, activities and entertainments, etc.

\subsection{Connection channel}

With the help of highly capable transportation, cities can be constructed through the rolling out of networks across wider and wider spaces (from cities, to urban morphology, and then international territories). Described by Stan Allen as 'the oldest and most persistent organising devices' [26], such transport networks could always be inserted into the urban fabric according to its hierarchy. Thus, the planning method based on the grid is actually a pragmatic way of dividing the territory, as well as standardising the elements in geometric method to connect veins of transport. Like Algiers, as a typical post-Fordist city, experiencing rapid urban sprawl and transformation of industry, new urban forms have been stimulating over time.

\section{Conclusion}

From Casbah in the French Colonial period to today, the community of the city has tended to be more self-organised. Infrastructure construction, regional accessibility and connection have long-term potential to influence the urban area. However, transportation does not only affect urban form but also fundamentally changes elements of society, politics and the economy. As the spine of urban fabric, the traffic circulation had a significant role in guiding and influencing the direction of the city sprawl and urban morphology. 
As 'Made in Tokyo' [28] indicated, transportation infrastructures have been relieved of their functional or programmatic duties and now behave as a framework. As it was reported by BBC, ' $75 \%$ of the world's population will live in cities by 2050, putting pressure on the transport network', the emergency services and the utilities should be stretched to capacity [29]. Although this article has explored the mechanisms and theoretical feasibility of applying transportation infrastructures to multifunctional urban nodes, to predict and protect human living space in advance, there still exist some problems, which should be thought about and well catered for their function and quality (i.e. scale, noise, pollution etc.). Moreover density, layout, block relations, solid-void and ground conditions are other important considerations in shaping urban morphology, so applying the same methodology to these features will help to inspire the idea to fulfill the prophecy: 'Tomorrow's city will be networked' [30].

\section{References}

[1] Buhl, J., Gautrais, J., Reeves, N., Solé, R. V., Valverde, S., Kuntz, P., \& Theraulaz, G., Topological patterns in street networks of self-organized urban settlements. The European Physical Journal B-Condensed Matter and Complex Systems, 49(4), 513-522, 2006.

[2] Weber, K. M., Transforming large socio-technical systems towards sustainability. Innovation: the European Journal of Social Science Research, 16(2), 155-175, 2003.

[3] Baudelaire, Charles, The Painter of Modern Life and Other Essays, edited and translated by Jonathan Mayne. London: Phaidon Press, 1964.

[4] Graham, S. \& Marvin, S., Splintering urbanism: networked infrastructures, technological mobilities and the urban condition. Routledge, 2001.

[5] Asami, Y., Istek, C., \& Kubat, A. S., Characterization of the street networks in the traditional Turkish urban form. Environment and Planning B, 28(5), 777-796, 2001.

[6] Kristian S. G., All International Politics Is Local: The Diffusion of Conflict, Integration, and Democratisation, The Unibersity of Michigan Press, 2002.

[7] ZEYNEP, Ç., Urban forms and colonial confrontations: Algiers under French rule, University of California Press, 1997.

[8] Graham, S. \& Marvin, S., Splintering urbanism: networked infrastructures, technological mobilities and the urban condition. Routledge, 2001.

[9] Stephen G. and Simon M., Splintering Urbanism makes an international and interdisciplinary analysis of the complex interactions, British Library Cataloging in Publication Data, 2001.

[10] Camagni, R., Gibelli, M. C., \& Rigamonti, P., Urban mobility and urban form. Ecological economics, 40(2), 199-216, 2002.

[11] Graham, S., \& Marvin, S., Splintering urbanism: networked infrastructures, technological mobilities and the urban condition. Routledge, 2001. 
[12] Stephen G. and Simon M., Splintering Urbanism makes an international and interdisciplinary analysis of the complex interactions, British Library Cataloging in Publication Data. 2001.

[13] ZEYNEP, Ç. Urban forms and colonial confrontations: Algiers under French rule, University of California Press, 1997.

[14] Tarr, J. and Dupuy G.(eds), Technology and the rise of the networked city in Europe and North American, Philadelphia: Temple University Press, 322-38, 1998.

[15] Stephen G. and Simon M. Splintering Urbanism makes an international and interdisciplinary analysis of the complex interactions, British Library Cataloging in Publication Data, 2001.

[16] Ward, S. (Ed.). 1992. Garden City (Vol. 15). Taylor \& Francis.

[17] Hall, P. 2002, Cities of Tomorrow: An Intellectual History of Urban Planning and Design in the Twentieth Century. Oxford: Blackwell.

[18] Hall, P. 2002, Cities of Tomorrow: An Intellectual History of Urban Planning and Design in the Twentieth Century. Oxford: Blackwell.

[19] Newman P.W.G. and Kenworthy, J.R., Cities and automobile dependence. An international sourcebook. Gower Technical, Aldershot, 1989.

[20] Conzen, M. R. G., 'The use of town plans in the study of urban history', in Dyos, H. J. (ed.), The study of urban history, London, 113-30 [HT111/DYOS] PDF, 1968.

[21] Berlucchi, Nicola (2000). “Aldo Rossi: ricostruzione del teatro La Fenice [Category:Articles containing Italian language text]”. Area 51.

[22] Hansen, W.G., 'How accessibility shapes land use'. Journal American, Institute of Planners, 25, 73-91, 1959.

[23] Bhabha, Homi K. The Location of Culture. London: Routledge, 1994.

[24] Tarr, J. and Dupuy G.(eds), Technology and the rise of the networked city in Europe and North American, Philadelphia: Temple University Press, 322-38, 1998.

[25] Eckardt, F. and Eade, J. (eds.) Ethnically diverse city. Future Urban Research in Europe, 4, Berliner-Wissenschaafts-Verlag, pp.85-114], 2011.

[26] Stan, A., from object to field, AD (Architectural Design), Vol 67, 1997.

[27] Tarr, J. and Dupuy G. (eds), Technology and the rise of the networked city in Europe and North American, Philadelphia: Temple University Press, 322-38, 1998.

[28] Junzo, K \& Momoyo, K \& Yoshihiaru,T. 2001. Made in tokyo, Kajima Institute Publishing.

[29] BBC News - Tomorrow's cities: Do you want to live in a smart city? Jane Wakefield, Technology reporter, 2013. http://www.bbc.co.uk/news/ technology-22538561.

[30] Gérard Mestrallet, Chairman and CEO, GDF-SUEZ, Cities of Tomorrow: Rediscovering Energy. ed. G. S. International Relations Directorate. Paris: GDF SUEZ, 2010. 